\title{
Asiatic Acid Attenuates Aluminium Chloride- Induced Behavioral Changes, Neuronal Loss and Astrocyte Activation in Rats
}

Jyoti Suryavanshi

Jawaharlal Nehru University

Chandra Prakash

Jawaharlal Nehru University

Deepak Sharma ( $\sim$ sharmadeepakjnu@gmail.com )

Jawaharlal Nehru University https://orcid.org/0000-0002-9929-3119

\section{Research Article}

Keywords: Aluminium, asiatic acid, oxidative stress, neurotoxicity, neuronal loss, neuroprotection

Posted Date: November 8th, 2021

DOl: https://doi.org/10.21203/rs.3.rs-1023676/v1

License: (c) (1) This work is licensed under a Creative Commons Attribution 4.0 International License.

Read Full License 


\section{Abstract}

Aluminium (Al) is a potent neurotoxic metal known to cause neurodegeneration. Al exposure generates oxidative stress by accumulation of reactive oxygen species in the brain that is followed by the activation of neuronal cell death. Asiatic acid (AA), the major bioactive compound of Centella asiatica (a medicinal plant), act as multifunctional drug as well as an antioxidant. Thus, the present study aimed to investigate the potential neuroprotective effects of AA against Al neurotoxicity. Rats were orally administered with $100 \mathrm{mg} / \mathrm{kg}$ b. wt. of aluminium chloride $\left(\mathrm{AlCl}_{3}\right)$ dissolved in distilled water for 8 weeks or $A A(75 \mathrm{mg} / \mathrm{kg} \mathrm{b}$. wt.) in combination with Al. The results showed that $\mathrm{AlCl}_{3}$-intoxication caused significantly impaired memory, enhanced anxiety-like behavior, increased acetyl cholinesterase (AChE) activity and higher level of malondialdehydes (MDA) along with concomitantly decreased activities of superoxide dismutase (SOD) and catalase (CAT) in the cortex and hippocampus regions of the brain. In addition, Al exposure caused neuronal loss and enhanced reactive astrogliosis in both regions. However, co-administration of AA with $\mathrm{AlCl}_{3}$ significantly attenuated behavioral alterations, improved AChE, SOD and CAT activities and decreased MDA level. Further, the study demonstrated that AA attenuated neuronal loss and reactive astrogliosis in rat brain. In conclusion, AA could protect rat brain from Al toxicity by inhibiting oxidative stress, neuronal loss and reactive astrogliosis.

\section{Introduction}

Aluminium (Al) is a highly abundant neurotoxic metal that affects the human population around the world. Besides the presence in nature, antacids, foils, cosmetics, deodorants, vaccines etc. are also the sources of Al exposure. Hence, high abundance of $\mathrm{Al}$ in the environment makes human at high risk of its exposure via air, water and food (Krewski et al. 2007). Normal Al concentration in human body is in the range of 0.1-0.4 $\mu \mathrm{g} \mathrm{Al} / \mathrm{gm}$ tissue in dry wt. (Exley and House 2011). Presence of Al beyond this limit results in multiple pathological conditions including Alzheimer's disease, Autism, multiple sclerosis (Exley and Clarkson 2020), Parkinson's disease and Dementia (Maya et al. 2016) and causes severe neurotoxic effects (Exley 2014). The human population exposed to Al result in its higher concentration in different tissues including brain (Julka and Gill 1996). Moreover, the animal studies have also demonstrated that Al accumulates in different brain regions following its long-term exposure (Nehru and Bhalla 2006; Sethi et al. 2008).

Accumulating body of evidence demonstrated that neurotoxic action of Al is associated with impairment of memory and coordination, anxiety, tremor and jerking movements (Kiesswetter et al. 2007). Multiple animal studies observed that extended contact to Al can cause neurobehavioral, pathological and neurochemical changes in brain which in turn weaken spatial memory and learning (Sethi et al. 2009; Junior et al. 2013; Prakash et al. 2013; Zhao et al. 2020). Acetylcholine esterase (AChE), a prominent marker of neurotoxicity as well as a key modulator of memory and hippocampal plasticity has been reported to be altered following Al exposure (Kaizer et al. 2005). 
Brain is considered highly vulnerable to Al toxicity, owing to the presence of non-dividing neuronal cells. Moreover, the tissue has high content of polysaturated fatty acids that make it extremely sensitive to free radicals produced following toxic insults (Joffre 2019). Emerging evidence from the literature suggest that Al exposure generates reactive oxygen species (ROS) which in turn imbalance pro/anti-oxidant systems. Production of ROS disrupts cellular antioxidant defense system and is linked with multiple neurodegenerative disorders (Lee et al. 2021). Malondialdehyde (MDA) is an important marker of lipid peroxidation (LPO) and depicts oxidative stress status of cells. Enhanced oxidative stress further causes damage to cellular biomolecules such as DNA, lipids and proteins, hence, cells commence under more oxidative stress (Singh et al. 2019). Studies have shown that Al causes LPO and protein oxidation (PO) along with decline in antioxidant activities viz glutathione peroxidase, superoxide dismutase (SOD), catalase (CAT) (Prakash and Kumar 2013; Nehru and Bhalla 2006).

Astrocytes play a crucial role in supporting neurons by providing glucose and neurotrophic factors and protecting them from oxidative stress. Studies demonstrated that in response to toxic insults or disease states, neuronal health gets affected, where astrocytes play a critical role in survival and functioning of neurons (Sofroniew and Vinters 2010; Wang and Xu 2020). Multiple evidences from animal studies indicated that Al toxicity causes astrogliosis and neuronal cell death (Junior et al. 2013; Laabbar et al. 2021). The evaluation of neuronal loss and reactive astrogliosis are important toxicity indicators. Hence, maintenance and protection of astrocytes can be of therapeutic use and modulate functioning and degeneration of neurons (Jeong et al. 2014).

Centella asiatica (C. asiatica), an important medicinal herb from the Apiaceae family, has been in use from decades in Ayurvedic and Chinese medicines as well as a memory enhancement tonic (Puttarak et al. 2017; Sun et al. 2020). C. asiatica has been reported to have antioxidant, antiapoptotic, mitoprotective and neuroprotective properties (Prakash and Kumar 2013; Tabassum et al. 2013; Sun et al. 2020). Asiatic acid (AA) is one of the most important bioactive compound responsible for its antioxidant and other therapeutic properties (Nagoor Meeran et al. 2018; Krishnamurthy et al. 2009). AA attenuates cognitive deficit in an animal model of monosodium glutamate-induced dementia and protects SH-SY5Y cells against glutamate-induced apoptosis (Xu et al. 2012). In addition, AA exerts protective effect against spinal cord injury by suppressing inflammation and oxidative stress (Jiang et al. 2016). Recent studies investigated that AA mitigate Al-induced Alzheimer disease-associated pathologies such as behavioral impairment, $A \beta$ burden and activation of inflammatory, and apoptotic pathways (Rather et al. 2018, 2019).

Therefore, in this study we examined the effect of AA in spatial memory and anxiety in aluminium chloride $\left(\mathrm{AlCl}_{3}\right)$-exposed adult male Wistar rats. Furthermore, AChE activity, oxidative stress indices (LPO, and activities of SOD and CAT), and neurons morphology were evaluated. The neuronal density and reactive astrogliosis were also assessed using immunostaining against neuronal nuclear protein (NeuN) and glial fibrillary acid protein (GFAP).

\section{Materials And Methods}




\section{Chemicals used}

Carboxymethylcellulose (CMC), $\mathrm{AlCl}_{3}, \mathrm{AA}, 5,5$ - dithiobis-2-nitrobenzoic acid (DTNB), pyrogallol, acetylthiocholine (ATch), Tris base, thiobarbituric acid (TBA), 4',6-diamidino-2-phenylindole (DAPI) and cresyl violet (CV) were procured from Sigma Aldrich, St. Louis, USA. Triton x 100 and bovine serum albumin (BSA) were obtained from G-Biosciences, St. Louis, USA. Sodium dodecyl sulphate (SDS), Ethylene diamine tetraacetic acid (EDTA) and dibutyl phthalate polystyrene xylene (DPX) were from Sisco Research Laboratory, Mumbai, India. Analytical grade chemicals and double distilled water were used during the entire study.

\section{Animals and their care}

Male Wistar rats weighing 180-200 g were procured from Central Laboratory of Animal Research, Jawaharlal Nehru University (JNU), New Delhi, provided ad libitum supply of water and food and maintained standard hygienic conditions with a light/dark cycle of 12 -h and $25-28{ }^{\circ} \mathrm{C}$ temperature. The rats used in the present study were approved from the Institutional Animal Ethics Committee of JNU, New Delhi and all the experiments were done as per the Committee for the Purpose of Control and Supervision of Experiments on Animals guidelines.

\section{Experimental design}

Rats used for experiment were divided randomly into four groups: (1) Control: rats administered with same volume of distilled water (DW) and $\mathrm{CMC}, 0.5 \%$ as administered to $\mathrm{AlCl}_{3}$ and AA-treated group. (2) $\mathrm{AlCl}_{3}$-intoxicated: rats received $\mathrm{AlCl}_{3}$ dissolved in DW (100 mg/kg b. wt., orally) for 8 weeks. (3) $\mathrm{AlCl}_{3}+$ AA-treated: rats administered with $\mathrm{AlCl}_{3}$ and $\mathrm{AA}(75 \mathrm{mg} / \mathrm{kg}$ b. wt., orally) dissolved in $0.5 \% \mathrm{CMC}$ for 8 weeks. (4) AA-treated: rats were administered with AA alone dissolved in $0.5 \% \mathrm{CMC}$ for 8 weeks.

Doses of $\mathrm{AlCl}_{3}$ (Prakash and Kumar 2013) and AA (Krishnamurthy et al. 2009; Rather et al. 2018) were taken from literature. All administrations were done 5 days per week via oral gavage for 8 weeks. DW and $0.5 \% \mathrm{CMC}$ were employed as vehicle for $\mathrm{AlCl}_{3}$ and $\mathrm{AA}$ respectively. Details of schematic outline of the experimental design including studied parameters have been given in Fig. 1.

\section{Behavioral studies}

\section{Morris water maze (MWM) test}

Spatial learning and memory capabilities of rats $(n=6)$ was examined using MWM test as the method of Morris (1984) with few alterations. The water maze comprised of a circular tank painted-black (Diameter: $168 \mathrm{~cm}$ and Depth: $50 \mathrm{~cm}$ ), having cues of various shapes. A circular (hidden) platform painted-black (Diameter: $15 \mathrm{~cm}$ ) was placed in the middle of a quadrant, $2.0 \mathrm{~cm}$ beneath the water surface, for rats to flee from swimming. The tank perimeter was labeled with east, west, north and south. Prior to experimentation randomly picked rats were acclimatized to the setup and tested for their swimming capabilities. Subsequently, rats were kept once in each quadrant of the water tank, their face towards the 
tank wall for all four entry points. Rats were guided to locate the platform and let them to stay for 20 seconds, in case they failed to spot the platform in 120 seconds. MWM test was conducted for 5 consecutive days and recorded using a camera placed on the top of the tank. The test was performed just amid 11:00 AM and 3:00 PM, to eliminate variations.

\section{Light and dark (L\&D) test}

L\&D test in rats $(n=6)$ was carried out to access the anxiety-like behavior as described previously by Ramos et al. (2003). The light/dark setup made of plexiglass $(48 \mathrm{~cm} \times 24 \mathrm{~cm} \times 27 \mathrm{~cm})$ and was separated through a barrier into two chambers consisted of a doorway $(10 \mathrm{~cm} \times 10 \mathrm{~cm})$. One chamber was made dark with a lid while white chamber was illuminated by a bulb $(60-\mathrm{W})$ placed above the apparatus. On the experiment day, rats were transferred to the dark room and remained undisturbed for 2 h. Afterwards rats were centrally positioned in the lit chamber, facing opposite to the dark compartment. Rats were permitted to freely explore the chamber for $5 \mathrm{~min}$ and recorded. The defecation index, number of transitions between L\&D chamber and time spent in the light chamber were calculated.

Open field test (OFT)

The OFT task was performed to validate the anxiety-like behavior of rats $(n=6)$ in a open field arena. Rats were examined for their exploratory behavior in this test as described by Sethi et al. (2009). Rats were positioned in middle of the arena and locomotor activity was analysed as the number of central and peripheral square entries. The number of squares entries done by rats within a span of 5 min were recorded and faecal boli number was counted to calculate defecation index. Before every trial, the floor was thoroughly cleaned with $70 \%$ ethanol.

\section{Tissue homogenate preparation}

Rats were euthanized via passing a high flow rate of $\mathrm{CO}_{2}(16 \mathrm{~L} / \mathrm{min})$ and decapitated. The intact brain was isolated followed by dissecting out of cortex and hippocampus. The hippocampi of both sides (left and right) were combined to prepare one sample. All the samples were homogenized $(10 \% \mathrm{w} / \mathrm{v})$ with a tissue homogenizer using homogenizing medium (0.1 mM EDTA, $0.32 \mathrm{M}$ sucrose, $10 \mathrm{mM}$ Tris- $\mathrm{HCl}, \mathrm{pH}$ 7.4). The resulting mixture was then spun at $5000 \mathrm{xg}$ for $10 \mathrm{~min}$ at $4^{\circ} \mathrm{C}$ and then supernatant was transferred in a fresh tube and stored for the biochemical analysis. The protein concentration of each sample was measured by the Bradford (1976) method using BSA as standard.

\section{AChE activity}

AChE activity was estimated as per the method of Ellman et al. (1961), a reaction mixture comprised of $2.35 \mathrm{ml}$ sodium phosphate buffer (0.1M, pH 7.4), $0.2 \mathrm{ml}$ DTNB $(10 \mathrm{mM}), 0.2 \mathrm{ml}$ triton X100 (0.013\%), 0.05 $\mathrm{ml}$ tissue homogenate and $0.2 \mathrm{ml}$ of $10 \mathrm{mM}$ ATch. AChE activity was measured spectrometrically at 412 $\mathrm{nm}$ and results were expressed as nmol/ACh hydrolyzed/min/mg protein

\section{LPO assay}


LPO was measured as described by Kaizer et al. (2005) with few modifications. Tissue homogenate (50 $\mu \mathrm{l})$ was mixed with $2.5 \%$ SDS $(16.66 \mu \mathrm{l}), 20 \%$ acetic acid $(62.5 \mu \mathrm{l})$ and $1.33 \%$ TBA $(37.5 \mu \mathrm{l})$. Incubation for $1 \mathrm{~h}$ at $95^{\circ} \mathrm{C}$ was given to the reaction mixture in the water bath. Then, samples were cooled and centrifuged for $10 \mathrm{~min}\left(4000 \times \mathrm{g}, 4^{\circ} \mathrm{C}\right)$. Subsequently, the absorbance of thiobarbituric acid-reactive substances was recorded at $532 \mathrm{~nm}$ from the organic layer (supernatant). The results were expressed as nmol MDA/mg protein.

\section{Assays of antioxidant enzymes SOD activity assay}

The activity of SOD was estimated as per the method of Marklund and Marklund (1974). Briefly, pyrogallol solution $(20 \mathrm{mM}, 1 \mathrm{ml})$ was mixed with tris-buffer $(50 \mathrm{mM}, 1 \mathrm{ml})$, followed by addition of tissues homogenate $(50 \mu \mathrm{l})$. Absorbance of the reaction mixture was measured at $420 \mathrm{~nm}$. Enzyme essential for $50 \%$ inhibition was considered as $1 \mathrm{U}$ of SOD activity and the results were expressed as $\mathrm{U} / \mathrm{mg}$ protein.

\section{CAT activity assay}

The activity of CAT was estimated as per the method of Koroliuk et al. (1988), with slight modifications. The assay mixture was prepared with $0.1 \mathrm{ml}$ tissue homogenate and potassium phosphate buffer (50 $\mathrm{mM}, \mathrm{pH} 7.0)$, consisting of $30 \% \mathrm{H}_{2} \mathrm{O}_{2}$. Then, ammonium molybdate $(32.4 \mathrm{mM})$ was added to stop the reaction. The absorbance was measured at $405 \mathrm{~nm}$ and result was expressed as $\mu \mathrm{mol} \mathrm{H}_{2} \mathrm{O}_{2}$ oxidized/min/mg protein.

\section{Sample preparation for immunofluorescence and histopathology}

Rats were perfused transcardially with saline $(0.9 \%)$ and $2 \%$ paraformaldehyde (PFA). Afterwards, brain was post-fixed with $2 \%$ PFA overnight and later passed through 10,20 , and $30 \%$ of sucrose solutions, finally stored in $30 \%$ sucrose solution. Coronal sections ( $15 \mu \mathrm{m}$; IF and $30 \mu \mathrm{m}$; CV staining) were cut with the help of Cryostat (Leica CM 1860, Germany) and affixed over slides coated with gelatin.

\section{Histopathological study}

Histopathological study was carried out by CV staining. Briefly, the tissue sections were stained with CV after air-drying for few min. Afterwards, a graded series of alcohol was used to dehydrate the sections and then cleared with xylene by dipping twice ( 5 min each). Lastly, slides were mounted with DPX, coverslipped and observed with a light microscope (Motic Instruments Co. Ltd., Chengdu, China).

\section{Immunofluorescence examination}

For immunoreactivity study, sections were air-dried at room temperature for a few min followed by 3 washes of phosphate buffer saline (PBS) for 5 min each. Next, incubated for 10 min with $0.5 \%$ TritonX100 was given, followed by PBS washes (3 times). Nonspecific antigens were blocked by $3 \%$ normal 
goat serum. Then the sections were covered with mouse anti-GFAP (3\% BSA, 1:100 dilutions, Invitrogen, Carlsbad, USA) and mouse anti-NeuN (3\% BSA, 1:100 dilutions, GenTex, Inc. CA, USA) monoclonal antibodies and incubated overnight at $4^{\circ} \mathrm{C}$. After 3 washes of PBS, sections were covered with Alexa Fluor 488-conjugated goat anti-mouse secondary antibody (Invitrogen, Carlsbad, USA; 1:200) and incubated in dark for $2 \mathrm{~h}$ at room temperature, then washed with PBS thrice. Next, Slides were stained with DAPI for 10 min to visualize nucleus, followed by PBS washes (3 times). Finally, sections were mounted with Fluoromount ${ }^{\mathrm{TM}}$ Aqueous Mounting Medium and cover slipped. Sections were observed with fluorescence microscope (Nikon Eclipse 90i, Tokyo, Japan), images were taken and analysed.

\section{Statistical analysis}

Statistical analyses for study were carried out using SigmaStat 3.5 (Systat Software Inc., San Jose, CA, USA). Data were enunciated as mean \pm SEM. Statistical analysis was performed with one-way analysis of variance (ANOVA) by using Holm-Sidak post hoc test'.

\section{Results}

\section{Effect of AA on behavioral studies}

\section{MWM test}

MWM test was performed to examine memory impairment by monitoring average escape latency to locate a camouflaged platform in experimental rats. Results demonstrated that $\mathrm{AlCl}_{3}$-intoxicated rats displayed significantly extended escape latency on $2 \mathrm{nd}$, 3rd, 4th, and 5th day than respective control rats. However, the co-administration of $\mathrm{AA}$ along with $\mathrm{AlCl}_{3}$ significantly reduced the escape latency as compared to $\mathrm{AlCl}_{3}$-intoxicated rats on respective days. The rats treated with $\mathrm{AA}$ only exhibited no significant differences in escape latency with respect to control rats. These results suggested that supplementation of AA rescued from spatial learning and memory deficits in the $\mathrm{AlCl}_{3}$-intoxicated rats (Fig. 2).

\section{L\&D test}

As presented in Table $1 \mathrm{AlCl}_{3}$-intoxicated rats exhibited a significant increase in defecation index, number of transitions and lesser time spent in light chamber as compared to the control rats, this shows the anxiety-like behavior in $\mathrm{AlCl}_{3}$-intoxicated of rats. $\mathrm{AA}$ co-administration with $\mathrm{AlCl}_{3}$ significantly decreased defecation index, number of transitions and increased time spent in the light chamber with respect to $\mathrm{AlCl}_{3}$-intoxicated rats. The rats treated with $\mathrm{AA}$ alone showed no significant differences in these parameters in comparison to control rats. These results suggest AA supplementation improves anxietylike behavior induced by $\mathrm{AlCl}_{3}$-intoxication. 
Table 1

Effect of AA administration on OFT and L/D tests in $\mathrm{AlCl}_{3}$-intoxicated rats.

\begin{tabular}{|c|c|c|c|c|}
\hline OFT parameters & Control & $\mathrm{AlCl}_{3}$ & $\mathrm{AlCl}_{3}+\mathrm{AA}$ & AA \\
\hline $\begin{array}{l}\text { Centre square } \\
\text { entries }\end{array}$ & $3.333 \pm 1.506$ & $0.429 \pm 0.535^{\star \star}$ & $3.000 \pm 1.000^{\# \#}$ & $3.500 \pm 1.643$ \\
\hline $\begin{array}{l}\text { Peripheral square } \\
\text { entries }\end{array}$ & $1.833 \pm 0.753$ & $3.429 \pm 0.976^{\star *}$ & $2.000 \pm 0.707^{\#}$ & $1.833 \pm 0.983$ \\
\hline $\begin{array}{l}\text { Defecation } \\
\text { index }\end{array}$ & $2.167 \pm 1.835$ & $5.571 \pm 1.397^{\star \star}$ & $2.800 \pm 0.837^{\#}$ & $2.167 \pm 1.835$ \\
\hline \multicolumn{5}{|l|}{ L/D test parameters } \\
\hline Time spent in light & $95.000 \pm 6.812$ & $26.667 \pm 8.824^{\star \star \star}$ & $60.500 \pm 7.007^{\# \# \#}$ & $97.333 \pm 6.282$ \\
\hline No. of transitions & $8.833 \pm 1.169$ & $3.167 \pm 1.835^{\star \star \star}$ & $5.667 \pm 0.816^{\#}$ & $7.500 \pm 1.871$ \\
\hline Defecation index & $1.500 \pm 1.049$ & $5.000 \pm 1.265^{\star \star \star}$ & $1.833 \pm 0.983^{\# \# \#}$ & $1.667 \pm 1.633$ \\
\hline \multicolumn{5}{|c|}{$\begin{array}{l}\text { Values are expressed as mean } \pm \text { SEM }(n=6) \text { in each group. }{ }^{*} \mathrm{p} \leq 0.05,{ }^{* *} \mathrm{p}<0.01,{ }^{* \star} \mathrm{p}<0.001 \text { significantly } \\
\text { different from control group; }{ }^{\#} \mathrm{p} \leq 0.05,{ }^{\# \#} \mathrm{p} \leq 0.01,{ }^{\# \# \#} \mathrm{p} \leq 0.001 \text { significantly different } \mathrm{AlCl}_{3} \text {-intoxicated } \\
\text { group. }\end{array}$} \\
\hline
\end{tabular}

\section{OFT test}

Anxiety-like behavior was further validated by OFT. Al-intoxicated rats exhibited a significantly increased defecation index and decreased locomotor activity compared with control rats; this also shows the anxiety-like behavior of rats after Al exposure. AA co-administration significantly declined the defecation index and increased locomotor activity in OFT in comparison to $\mathrm{AlCl}_{3}$-intoxicated rats. While, the alone treatment of AA caused no significant changes in these parameters in comparison to control rats. Thus, results suggested that $\mathrm{AA}$ may have reversed the effects of $\mathrm{AlCl}_{3}$ exposure (Table 1).

\section{Effect of AA on AChE activity}

The results exhibited a significantly enhanced AChE activity in Al-intoxicated rats as compared to the controls both in cortex and hippocampus. Co-administration of AA effectively declined AChE activity both regions as compared to Al-intoxicated rats. The alone treatment of AA showed no significant difference as compared to control rats. Thus, the result suggested that AA significantly decreased the AChE activity in $\mathrm{AlCl}_{3}$-intoxicated rat brain (Fig. 3A).

\section{Effect of AA on LPO}


The effect of $\mathrm{AA}$ on $\mathrm{LPO}$ in $\mathrm{AlCl}_{3}$-intoxicated rats is presented in Fig. 3B. Results showed significantly increased $\mathrm{LPO}$ in $\mathrm{AlCl}_{3}$-intoxicated rats in both cortex and hippocampus in contrast to controls. Contrary to this, $\mathrm{AA}$ co-administered with $\mathrm{AICl}_{3}$ displayed a significant decline in $\mathrm{LPO}$ of cortex and hippocampus regions as compared to $\mathrm{AlCl}_{3}$-intoxicated rats. The treatment of $\mathrm{AA}$ alone caused no significant difference as compared to controls. Thus, it can be observed from the result that AA reduced level of LPO increased by $\mathrm{AlCl}_{3}$ intoxication.

\section{Effect of AA on antioxidant enzymes activities}

A significant decline in the SOD activity in cortex and hippocampus was observed in Al-intoxicated rats with respect to controls; whereas rats treated with $\mathrm{AA}$ along with $\mathrm{AlCl}_{3}$ exhibited a significant increase in both cortex as well as hippocampus when compared to $\mathrm{AlCl}_{3}$-intoxicated rats (Fig. 4A). The alone treatment of AA demonstrated no significant difference in SOD activity as compared to controls.

The CAT activity showed a significant decline in cortex and hippocampus regions of $\mathrm{AlCl}_{3}$-intoxicated rats in comparison to controls; whereas rats treated with $\mathrm{AA}$ along with $\mathrm{AlCl}_{3}$ exhibited a significant increase in cortex and hippocampus as compared to $\mathrm{AlCl}_{3}$-intoxicated rats (Fig. 4B). The alone treatment of $\mathrm{AA}$ exhibited no significant difference in the CAT activity with respect to control rats. Overall, these results suggests that AA significantly increased the activity of antioxidant enzymes in $\mathrm{AlCl}_{3}$-intoxicated rats.

\section{Effects of AA on histopathology}

As presented in Fig. 5, CV-stained microscopic images demonstrated severe degeneration of neurons, as evident from pyknotic appearance and less intact cells in both cortex and hippocampus of $\mathrm{AlCl}_{3}{ }^{-}$ intoxicated rat group with respect to controls. Whereas, co-administration of $\mathrm{AA}$ with $\mathrm{AlCl}_{3}$ attenuated these neuronal changes in $\mathrm{AlCl}_{3}$-intoxicated rats. However, treatment of $\mathrm{AA}$ alone has shown no significant changes in both brain regions. Hence, $C V$ staining results suggested that $A A$ treatment remarkably prevented neuronal damage in both regions of brain.

\section{Effects of AA on astrocytes activation and neuronal loss}

NeuN positive cells significantly decreased in the $\mathrm{AlCl}_{3}$-intoxicated rats, whereas $\mathrm{AA}$ co-administration with $\mathrm{AlCl}_{3}$ resulted in higher NeuN positive cells as compared with $\mathrm{AlCl}_{3}$-intoxicated rats in the cortex and hippocampus as evident from optical density of NeuN positive cells. The alone treatment of AA resulted in no notable difference in the NeuN positive cells as compared to control rats (Fig. 6). These results showed that $A A$ treatment reversed the changes caused by $\mathrm{AlCl}_{3}$.

Al exposure has also found to increase the number of activated astrocytes and exhibited significant increase in GFAP immunoreactivity in the cortex and hippocampus when compared to controls. AA coadministered with $\mathrm{AlCl}_{3}$ caused a significant decrease in GFAP immunoreactive cells of the cortex and hippocampus in contrast to the $\mathrm{AlCl}_{3}$-intoxicated rats. Treatment of $\mathrm{AA}$ alone caused no significant change in the immunoreactivity of reactive astrocytes as compared to controls (Fig. 7). 


\section{Discussion}

Al is excessively occurring in the environment and human are easily exposed to it via gastrointestinal tract, lung, skin etc. Thus, Al can readily enter into blood circulation from where its travels to brain by crossing blood-brain-barrier (Kawahara et al. 2007). The half-life of Al is high, hence upon exposure it can accumulates in different body organs including brain and causes neurodegeneration (Yokel 2006; Wu et al. 2012).

Several human and animal studies indicated that Al toxicity causes behavioral alterations such as memory and learning ability as well as exerts anxiety-associated symptoms (Kumar and Gill 2009; Sethi et al. 2009; Krewski et al. 2007; Exley and House 2011). The MWM test analyses latency period to find a hidden platform is a standard test for determining the consolidation of memory impairment (D'Hooge and De Deyn 2001). Our results observed that AA ameliorated memory impairment caused by Al in rats. These results are in agreement to the study by Rather et al. (2018) demonstrated that AA improved memory consolidation in $\mathrm{AlCl}_{3}$-intoxicated rats. Moreover, OFT and light/dark tests are designed to evaluate the anxiety-like behavior in rodents. We observed that AA treatment reduces anxiety-like behavior in Al-intoxicated rats and indicated that AA have anxiolytic potential along with enhanced memory performance in Al-induced neurotoxicity.

Acetylcholine (ACh) metabolism play pivotal role in cognitive functions such as in spatial learning memory. The change in ACh concentration is associated with pathophysiology of multiple brain disorders (Luchicchi et al. 2014), where altered AChE activity is known to regulate the cholinergic transmission of brain. Al exposure has been reported to alter the AChE activity in the peripheral and central nervous system (Maya et al. 2016). In the present study, we observed elevation in AChE activity in Al-exposed rats whereas co-treatment of AA caused a significant decline of AChE activity in both cortex and hippocampus. Some previous studies have also demonstrated that AA actively competes with ACh at the esteratic site of AChE, thus inhibiting the activity of enzyme (Prakash and Kumar 2013; Rather et al. 2018). Hence, it can be speculated that suppression of AChE activity may have attenuated the Al-induced neurobehavioral changes especially learning and memory deficits.

Several evidences indicated the role of oxidative stress on Al-induced neurotoxicity (Kumar and Gill 2009). Moreover, Al-induced oxidative stress can be effectively ameliorated by restoring the impaired pro/antioxidant ratio (Kumar and Gill 2014). Hence, to evaluate the pro/antioxidant status of experimental animals, estimation of LPO, and activities of SOD and CAT was done. Our results demonstrated that administration of AA resulted in significant alterations of oxidative stress and cellular antioxidant level. We found a significant increase of MDA content in the cortex and hippocampus of $\mathrm{AlCl}_{3}$-intoxicated rats. Further, decline in SOD and CAT activities indicated the disruption of pro/antioxidant balance. Treatment of AA has reduced the MDA content and enhanced SOD and CAT activities. These results are in accordance with earlier findings demonstrating attenuation of oxidative stress and cellular antioxidant by AA (Rather et al. 2019; Loganathan and Thayumanavan 2018; Chen et al. 2019). 
Elevated oxidative stress can activate apoptotic cell death pathway and causes neurodegeneration (Kim et al. 2015). Hence, we studied the effect of Al and AA treatments on brain morphology in rats. Control rats depicted normal cellular architecture in the cortex and hippocampus of rats with well-differentiated and healthy neurons. CV-stained sections from $\mathrm{AlCl}_{3}$-intoxicated rats showed histological disorganization of neurons in both regions of brain. Further, the sections from $\mathrm{AlCl}_{3}$-intoxicated rats represented decreased cell density, along with darkly stained nuclei and shrunken cytoplasm. These pathological changes are indicative of neuronal injury and are in line with changes in the biochemical indices. Sections obtained from rats co-treated with Al and AA exhibited remarkable improvement in cell density of cortex as well as hippocampus regions and attenuated other architectural changes and suggested that neurons have recovered to their characteristic shapes. Evidence from previous studies have also demonstrated remarkable restoration of histological alterations of brain by AA in different pathological conditions (Tabassum et al. 2013; Nagoor Meeran et al. 2018).

The effect of AA on neuronal loss was further validated by immunohistochemical examination of NeuN, a marker of postmitotic mature neurons (Mullen et al. 1992). Al exposure was found to decrease the protein level of NeuN and results in accordance to the previous reports (Junior et al. 2013; Laabbar et al. 2021).

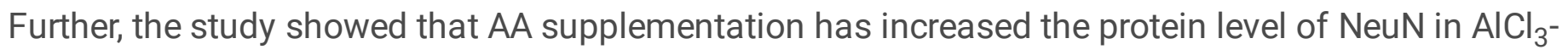
intoxicated rats that suggested protection of neurons in the both regions (cortex and hippocampus) of the brain. Previously, AA has also been reported to protect neurons by the alleviation of oxidative stress in different pathological conditions (Lee et al. 2014; Jiang et al. 2016, Rather et al. 2019). AA has been reported to prevent C2-ceramide-induced cell death of primary cortical neurons, by stimulation of oxidative defense pathways (Zhang et al. 2012) as well as improved learning and memory by the modulation of cholinergic and GABAergic neurotransmission (Nasir et al. 2011). The hippocampus is an important neurogenic region in the adult brain (Aimone et al. 2011; Sahay et al. 2011). It has been suggested that hippocampal adult neurogenesis may have enhanced by AA and may have also contributed in learning and memory consolidation.

Astrocytes play critical role for normal functioning of neurons by serving as "second line of defense" of the brain (Verhoog et al. 2020). Reactive astrogliosis is a process that occurs in response to pathological conditions and toxic insults-mediated neurodegeneration, where elevated expression of GFAP, is the hallmark of the reactive astrogliosis (Pekny and Pekna 2014). Compelling evidence suggest that Al intoxication causes inactivation of astrocytes (Ekong et al. 2017; Laabbar et al. 2021). In this study, we observed enhanced expression of GFAP positive cells in the cortex and hippocampus of $\mathrm{AlCl}_{3}$-intoxicated rats, that is indicative of reactive gliosis. While, AA treatment reduced the expression of GFAP in both brain regions, indicating that $A A$ attenuates the process of astroglial activation that may have also contributed in the protection of neurons. Numerous studies have demonstrated that the impairment of astroglial functions can cause neuronal degeneration (Aremu and Meshitsuka 2005; Meshitsuka and Aremu 2008). Hence, attenuation of reactive gliosis by AA may have contributed in the repairing processes of neuronal loss caused by Al. 


\section{Conclusion}

In summary, our observations suggested that $\mathrm{AA}$ treatment mitigated $\mathrm{AlCl}_{3}$-induced neurotoxicity by altering oxidative stress, neuronal loss and astroglial activation. Hence, AA might be beneficial against Alinduced neurotoxicity, however, thorough research is needed to know its exact mechanism of action. Hence, further studies are warranted to explore the link between $\mathrm{AlCl}_{3}$-mediated oxidative stress and associated neurodegeneration to establish the neuroprotective role of AA.

\section{Declarations}

\section{Authors contribution}

JS and DS designed the study. JS performed experiments, collected and analysed data, and prepared initial draft of the manuscript. CP assisted to analyse data, edited figures, table and manuscript. DS critically reviewed final version of manuscript. All authors approved the final version of the manuscript.

\section{Acknowledgements}

Authors would like to acknowledge the Council of Scientific and Industrial Research, New Delhi for providing financial assistance in the form of Junior Research Fellowship to JS.

\section{Ethics statement}

All procedures carried in rats were duly approved by the Institutional Animal Ethics Committee of JNU, New Delhi (IAEC code: 27/2018) and performed as per the guidelines of the Committee for the Purpose of Control and Supervision of Experiments on Animals, New Delhi, India

\section{Data availability}

The data will be available upon a reasonable request.

\section{Conflict of interest}

None

\section{References}

1. Aimone JB, Deng W, Gage FH (2011) Resolving new memories: a critical look at the dentate gyrus, adult neurogenesis, and pattern separation. Neuron 70(4):589-596. https://doi.org/10.1016/j.neuron.2011.05.010

2. Aremu DA, Meshitsuka S (2005) Accumulation of aluminum by primary cultured astrocytes from aluminum amino acid complex and its apoptotic effect. Brain Res 1031(2):284296. https://doi.org/10.1016/j.brainres.2004.06.090 
3. Bradford MM (1976) A rapid and sensitive method for the quantitation of microgram quantities of protein utilizing the principle of protein-dye binding. Anal Biochem 72:248-

254. https://doi.org/10.1016/0003-2697(76)90527-3

4. Chen D, Zhang XY, Sun J, Cong QJ, Chen WX, Ahsan HM, Gao J, Qian JJ (2019) Asiatic acid protects dopaminergic neurons from neuroinflammation by suppressing mitochondrial ROS production. Biomol Ther 27(5):442-449. https://doi.org/10.4062/biomolther.2018.188

5. D'Hooge R, De Deyn PP (2001) Applications of the Morris water maze in the study of learning and memory. Brain Res Rev 36(1):60-90. https://doi.org/10.1016/S0165-0173(01)00067-4

6. Ekong MB, Ekpo MM, Akpanyung EO, Nwaokonko DU (2017) Neuroprotective effect of Moringa oleifera leaf extract on aluminium-induced temporal cortical degeneration. Metab Brain Dis 32:14371447. https://doi.org/10.1007/s11011-017-0011-7

7. Ellman GL, Courtney KD, Andres V Jr, Feather-stone RM (1961) A new and rapid colorimetric determination of acetylcholinesterase activity. Biochem Pharmacol 7:88-

95. https://doi.org/10.1016/0006-2952(61)90145-9

8. Exley C (2014) What is the risk of aluminium as a neurotoxin? Expert Rev Neurother 14(6):589591. https://doi.org/10.1586/14737175.2014.915745

9. Exley C, Clarkson E (2020) Aluminium in human brain tissue from donors without neurodegenerative disease: A comparison with Alzheimer's disease, multiple sclerosis and autism. Sci Rep 10:7770. https://doi.org/10.1038/s41598-020-64734-6

10. Exley C, House E R (2011) Aluminium in the human brain. Monatsh Chem 142:357363. https://doi.org/10.1007/s00706-010-0417-y

11. Jeong HK, Ji KM, Min KJ, Choi I, Choi DJ, Jou I, Joe EH (2014) Astrogliosis is a possible player in preventing delayed neuronal death. Mol Cells 37(4):345-

355. https://doi.org/10.14348/molcells.2014.0046

12. Jiang W, Li M, He F, Bian Z, He Q, Wang X, Yao W, Zhu L (2016) Neuroprotective effect of asiatic acid against spinal cord injury in rats. Life Sci 157:45-51. https://doi.org/10.1016/j.lfs.2016.05.004

13. Joffre C (2019) Polyunsaturated fatty acid metabolism in the brain and brain cells. InFeed your mind-How does nutrition modulate brain function throughout life? IntechOpen.

https://www.intechopen.com/chapters/68423

14. Julka D, Gill KD (1996) Altered calcium homeostasis: a possible mechanisms of aluminium-induced neurotoxicity. Biochim Biophys Acta 1315(1):47-54. https://doi.org/10.1016/0925-4439(95)00100-X

15. Junior AF, Aguiar MS, Junior OS, Luana de Nazaré SS, Franco EC, Lima RR, de Siqueira NV, Feio RA, Faro LR, Gomes-Leal W (2013) Hippocampal neuronal loss, decreased GFAP immunoreactivity and cognitive impairment following experimental intoxication of rats with aluminum citrate. Brain Res 1491:23-33. https://doi.org/10.1016/j.brainres.2012.10.063

16. Kaizer RR, Corrêa MC, Spanevello RM, Morsch VM, Mazzanti CM, Gonçalves JF, Schetinger MR (2005) Acetylcholinesterase activation and enhanced lipid peroxidation after long-term exposure to 
low levels of aluminum on different mouse brain regions. J Inorg Biochem 99(9):18651870. https://doi.org/10.1016/j.jinorgbio.2005.06.015

17. Kawahara M, Konoha K, Nagata T, Sadakane $Y$ (2007) Aluminum and human health: its intake, bioavailability and neurotoxicity. Biol Trace Elem Res 18(3):211-220. https://doi.org/10.11299/BRTE.18.211

18. Kiesswetter E, Schäper M, Buchta M, Schaller KH, Rossbach B, Scherhag H, Zschiesche W, Letzel S (2007) Longitudinal study on potential neurotoxic effects of aluminium: I. Assessment of exposure and neurobehavioural performance of Al welders in the train and truck construction industry over 4 years. Int Arch Occup Environ Health 81:41-67. https://doi.org/10.1007/s00420-007-0191-2

19. Kim GH, Kim JE, Rhie SJ, Yoon S (2015) The role of oxidative stress in neurodegenerative diseases. Exp Neurobiol 24(4):325-340. https://doi.org/10.5607/en.2015.24.4.325

20. Koroliuk MA, Ivanova LI, Maĭorova IG, Tokarev VE (1988) Metod opredeleniia aktivnosti katalazy [A method of determining catalase activity]. Lab Delo (1):16-19.

21. Krewski D, Yokel RA, Nieboer E, Borchelt D, Cohen J, Harry J, Kacew S, Lindsay J, Mahfouz AM, Rondeau V (2007) Human health risk assessment for aluminium, aluminium oxide, and aluminium hydroxide. J Toxicol Environ Health B Crit Rev 10(Suppl 1):1-

269. https://doi.org/10.1080/10937400701597766

22. Krishnamurthy RG, Senut MC, Zemke D, Min J, Frenkel MB, Greenberg EJ, Yu SW, Ahn N, Goudreau J, Kassab M, Panickar KS, Majid A (2009) Asiatic acid, a pentacyclic triterpene from Centella asiatica, is neuroprotective in a mouse model of focal cerebral ischemia. J Neurosci Res 87(11):2541-2550. https://doi.org/10.1002/jnr.22071

23. Kumar V, Gill KD (2009) Aluminium neurotoxicity: neurobehavioural and oxidative aspects. Arch Toxicol 83:965-978. https://doi.org/10.1007/s00204-009-0455-6

24. Kumar V, Gill KD (2014) Oxidative stress and mitochondrial dysfunction in aluminium neurotoxicity and its amelioration: a review. Neurotoxicology 41:154-

166. https://doi.org/10.1016/j.neuro.2014.02.004

25. Laabbar W, Abbaoui A, Elgot A, Mokni M, Amri M, Masmoudi-Kouki O, Gamrani H (2021) Aluminum induced oxidative stress, astrogliosis and cell death in rat astrocytes, is prevented by curcumin. $\mathrm{J}$ Chem Neuroanat 112, 0891-0618. https://doi.org/10.1016/j.jchemneu.2020.101915

26. Lee KY, Bae ON, Weinstock S, Kassab M, Majid A (2014) Neuroprotective effect of asiatic acid in rat model of focal embolic stroke. Biol. Pharm. Bull 37(8):1397-1401. https://doi.org/10.1248/bpb.b1400055

27. Lee YM, He W, Liou YC (2021) The redox language in neurodegenerative diseases: oxidative posttranslational modifications by hydrogen peroxide. Cell Death Dis 12(1):1-

3. https://doi.org/10.1038/s41419-020-03355-3

28. Loganathan C, Thayumanavan P (2018) Asiatic acid prevents the quinolinic acid-induced oxidative stress and cognitive impairment. Metab Brain Dis 33(1):151-159. https://doi.org/10.1007/s11011017-0143-9 
29. Luchicchi A, Bloem B, Viaña JN, Mansvelder HD, Role LW (2014) Illuminating the role of cholinergic signaling in circuits of attention and emotionally salient behaviors. Front Synaptic Neurosci 6:24. https://doi.org/10.3389/fnsyn.2014.00024

30. Marklund S, Marklund G (1974) Involvement of the superoxide anion radical in the autoxidation of pyrogallol and a convenient assay for superoxide dismutase. Eur J Biochem 47(3):469-474. https://doi.org/10.1111/j.1432-1033.1974.tb03714.x

31. Maya S, Prakash T, Madhu KD, Goli D (2016) Multifaceted effects of aluminium in neurodegenerative diseases: A review. Biomed Pharmacother 83:746-

754. https://doi.org/10.1016/j.biopha.2016.07.035.

32. Meshitsuka S, Aremu DA (2008) (13)C heteronuclear NMR studies of the interaction of cultured neurons and astrocytes and aluminum blockade of the preferential release of citrate from astrocytes. J Biol Inorg Chem 13:241-247 (2008). https://doi.org/10.1007/s00775-007-0317-8

33. Morris R (1984) Developments of a water-maze procedure for studying spatial learning in the rat. $J$ Neurosci Methods 11(1):47-60. https://doi.org/10.1016/0165-0270(84)90007-4

34. Mullen RJ, Buck CR, Smith AM (1992) NeuN, a neuronal specific nuclear protein in vertebrates. Development 116(1):201-211. https://doi.org/10.1242/dev.116.1.201

35. Nagoor Meeran MF, Goyal SN, Suchal K, Sharma C, Patil CR, Ojha SK (2018) Pharmacological properties, molecular mechanisms, and pharmaceutical development of asiatic acid: a pentacyclic triterpenoid of therapeutic promise. Front Pharmacol 9:892. https://doi.org/10.3389/fphar.2018.00892

36. Nasir MN, Habsah M, Zamzuri I, Rammes G, Hasnan J, Abdullah J (2011) Effects of asiatic acid on passive and active avoidance task in male Spraque-Dawley rats. J Ethnopharmacol 134(2):203-209. https://doi.org/10.1016/j.jep.2010.12.010

37. Nehru B, Bhalla $P$ (2006) Aluminium-induced imbalance in oxidant and antioxidant determinants in brain regions of female rats: protection by centrophenoxine. Toxicol Mech Methods 16(1):2125. https://doi.org/10.1080/15376520500195541

38. Pekny M, Pekna M (2014) Astrocyte reactivity and reactive astrogliosis: costs and benefits. Physiol Rev 94:1077-1098. https://doi.org/10.1152/physrev.00041.2013

39. Prakash A, Kumar A (2013) Mitoprotective effect of Centella asiatica against aluminum-induced neurotoxicity in rats: possible relevance to its anti-oxidant and anti-apoptosis mechanism. Neurol Sci 34:1403-1409 (2013). https://doi.org/10.1007/s10072-012-1252-1

40. Prakash D, Gopinath K, Sudhandiran G (2013) Fisetin enhances behavioral performances and attenuates reactive gliosis and inflammation during aluminum chloride-induced neurotoxicity. Neuromol Med 15:192-208 (2013). https://doi.org/10.1007/s12017-012-8210-1

41. Puttarak P, Dilokthornsakul P, Saokaew S, Dhippayom T, Kongkaew C, Sruamsiri R, Chuthaputti A, Chaiyakunapruk N (2017) Effects of Centella asiatica (L.) Urb. on cognitive function and mood related outcomes: A Systematic Review and Meta-analysis. Sci Rep 7(1):1-2. https://doi.org/10.1038/s41598-017-09823-9 
42. Ramos A, Correia EC, Izídio GS, Brüske GR (2003) Genetic selection of two new rat lines displaying different levels of anxiety-related behaviors. Behav Genet 33:657-

668. https://doi.org/10.1023/A:1026131130686

43. Rather M.A, Justin-Thenmozhi A, Manivasagam T, Saravanababu C, Guillemin G J and Essa M M (2019) Asiatic acid attenuated aluminum chloride-induced tau pathology, oxidative stress and apoptosis via AKT/GSK-3 $\beta$ signaling pathway in wistar rats. Neurotox Res 35:1-14. https://doi.org/10.1007/s12640-019-9999-2.

44. Rather MA, Justin Thenmozhi A, Manivasagam T, Dhivya Bharathi M, Essa MM, Guillemin GJ (2018) Neuroprotective role of Asiatic acid in aluminium chloride induced rat model of Alzheimer's disease. Front Biosci 10:262-275. https://doi.org/10.2741/S514

45. Sahay A, Scobie KN, Hill AS, O'Carroll CM, Kheirbek MA, Burghardt NS, Fenton AA, Dranovsky A, Hen $\mathrm{R}$ (2011) Increasing adult hippocampal neurogenesis is sufficient to improve pattern separation. Nature 472:466-470. https://doi.org/10.1038/nature09817

46. Sayre LM, Perry G, Smith MA (2008) Oxidative stress and neurotoxicity. Chem Res Toxicol 21(1):172188. https://doi.org/10.1021/tx700210j

47. Sethi P, Jyoti A, Hussain E, Sharma D (2009) Curcumin attenuates aluminium-induced functional neurotoxicity in rats. Pharmacol Biochem Behav 93(1):31-39.

https://doi.org/10.1016/j.pbb.2009.04.005

48. Sethi P, Jyoti A, Singh R, Hussain E, Sharma D (2008) Aluminium-induced electrophysiological, biochemical and cognitive modifications in the hippocampus of aging rats. Neurotoxicology 29(6):1069-1079. https://doi.org/10.1016/j.neuro.2008.08.005

49. Sharma DR, Wani WY, Sunkaria A, Kandimalla RJ, Verma D, Cameotra SS, Gill KD (2013) Quercetin protects against chronic aluminum-induced oxidative stress and ensuing biochemical, cholinergic, and neurobehavioral impairments in rats. Neurotox Res 23(4):336-

357. https://doi.org/10.1007/s12640-012-9351-6

50. Singh A, Kukreti R, Saso L, Kukreti S (2019) Oxidative stress: a key modulator in neurodegenerative diseases. Molecules 24(8):1583. https://doi.org/10.3390/molecules24081583

51. Sofroniew MV, Vinters HV (2010) Astrocytes: biology and pathology. Acta Neuropathol 119(1):735. https://doi.org/10.1007/s00401-009-0619-8

52. Sun B, Wu L, Wu Y, Zhang C, Qin L, Hayashi M, Kudo M, Gao M, Liu T (2020) Therapeutic potential of Centella asiatica and its triterpenes: a review. Front Pharmacol 11:1373. https://doi.org/10.3389/fphar.2020.568032

53. Tabassum R, Vaibhav K, Shrivastava P, Khan A, Ahmed ME, Javed H, Islam F, Ahmad S, Siddiqui MS, Safhi MM, Islam F (2013) Centella asiatica attenuates the neurobehavioral, neurochemical and histological changes in transient focal middle cerebral artery occlusion rats. Neurol Sci 34(6):92533. https://doi.org/10.1007/s10072-012-1163-1

54. Verhoog QP, Holtman L, Aronica E, van Vliet EA (2020) Astrocytes as guardians of neuronal excitability: mechanisms underlying epileptogenesis. Front Neurol 11:591690. 
https://doi.org/10.3389/fneur.2020.591690

55. Wang JL, Xu CJ (2020) Astrocytes autophagy in aging and neurodegenerative disorders. Biomed Pharmacother 122:109691. https://doi.org/10.1016/j.biopha.2019.109691

56. Wu Z, Du Y, Xue H, Wu Y, Zhou B (2012) Aluminum induces neurodegeneration and its toxicity arises from increased iron accumulation and reactive oxygen species (ROS) production. Neurobiol Aging 33(1) 199:e1-12. https://doi.org/doi:10.1016/j.neurobiolaging.2010.06.018

57. Xu MF, Xiong YY, Liu JK, Qian JJ, Zhu L, Gao J (2012) Asiatic acid, a pentacyclic triterpene in Centella asiatica, attenuates glutamate-induced cognitive deficits in mice and apoptosis in SH-SY5Y cells. Acta Pharmacologica Sinica 33(5):578-587. https://doi.org/10.1038/aps.2012.3

58. Yokel RA (2006) Blood-brain barrier flux of aluminum, manganese, iron and other metals suspected to contribute to metal-induced neurodegeneration. J Alzheimer's Dis 10(2-3):223-253. https://doi.org/10.3233/JAD-2006-102-309

59. Zhang X, Wu J, Dou Y, Xia B, Rong W, Rimbach G, Lou Y (2012) Asiatic acid protects primary neurons against C2-ceramide-induced apoptosis. Eur J Pharmacol 679(1-3):51-59. https://doi.org/10.1016/j.ejphar.2012.01.006

60. Zhao Y, Dang M, Zhang W, Lei Y, Ramesh T, Veeraraghavan VP, Hou X (2020) Neuroprotective effects of Syringic acid against aluminium chloride induced oxidative stress mediated neuroinflammation in rat model of Alzheimer's disease. J Funct Foods 71:104009.

https://doi.org/10.1016/j.jff.2020.104009

\section{Figures}




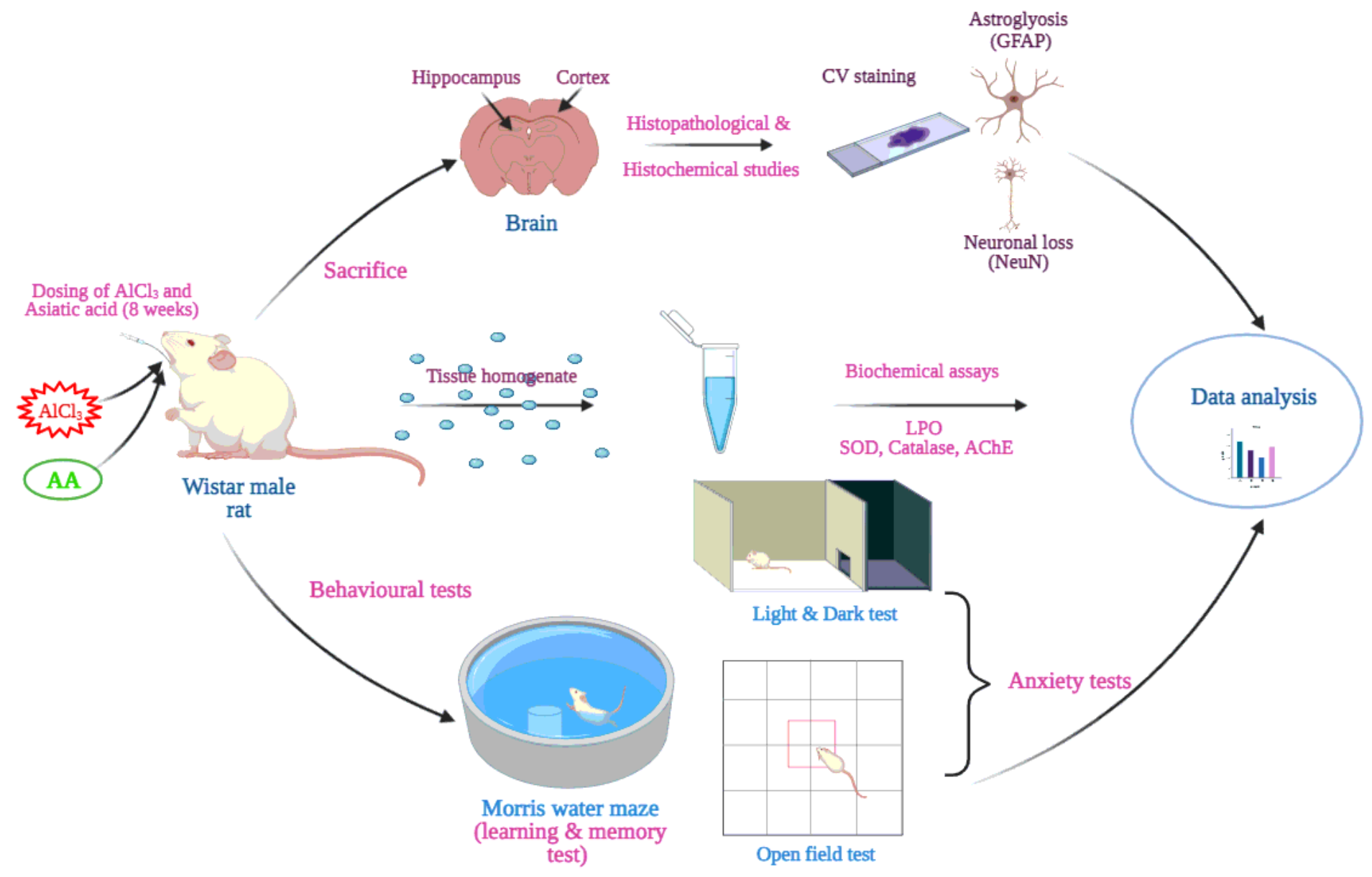

Fig.1

\section{Figure 1}

Schematic representation of experimental schedule performed in this study. 


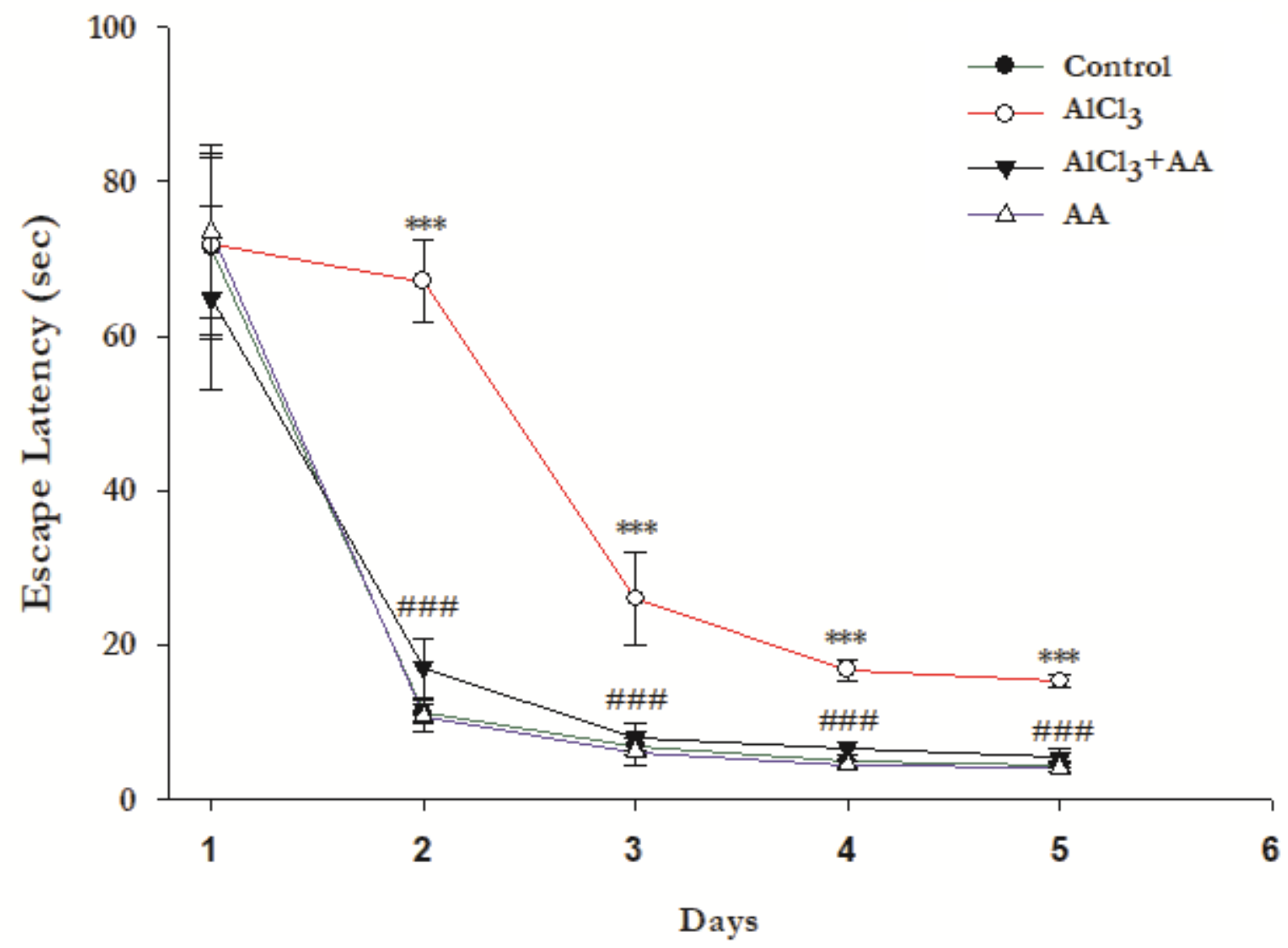

Fig. 2

Figure 2

Latency plot for platform search in $\mathrm{AICl} 3$ and AA-treated rat. The latency to locate the platform is more in AlCl3-intoxicated rats as compare to controls, while decreased in AA co-treated rats with respect to AlCl3intoxicated rats. Each data point represents mean \pm SEM of 6 rats. ${ }^{*} P \leq 0.05$ significantly different from control group and \#P $\leq 0.05$ compared with AlCl3-intoxicated group. 
[A]

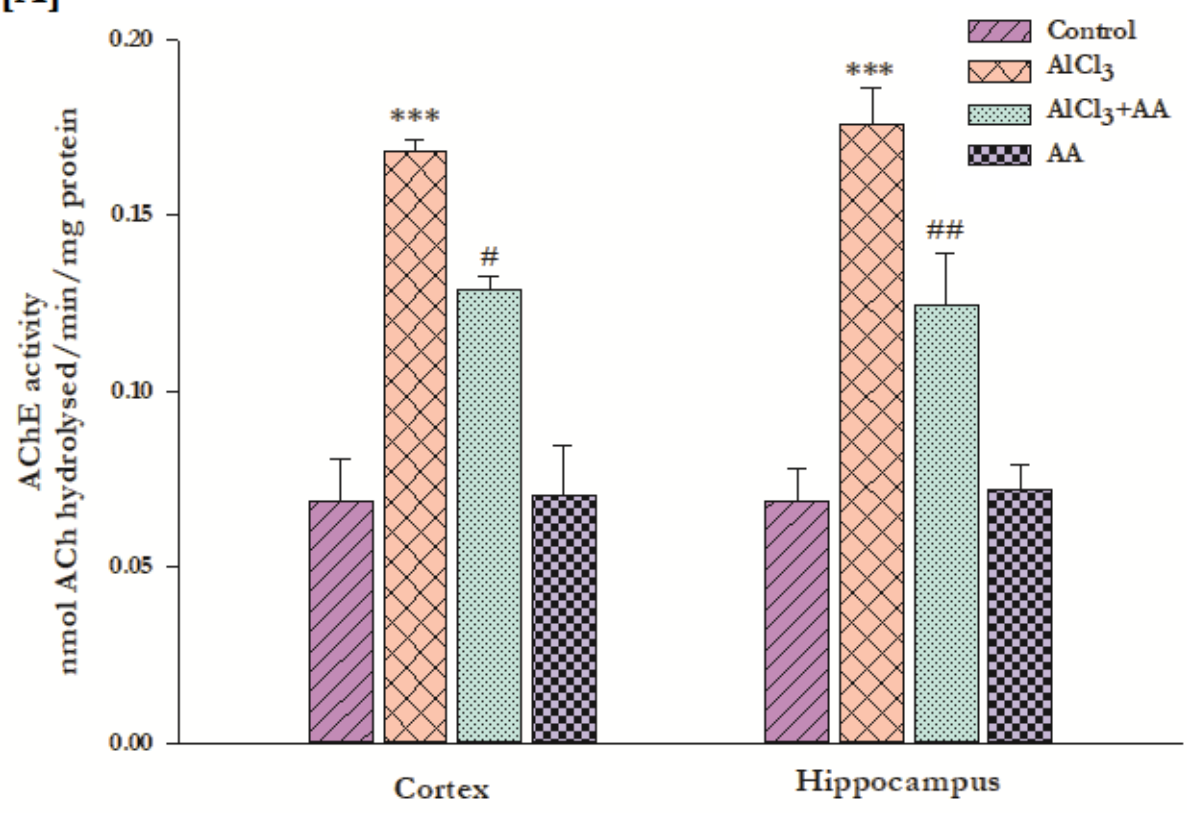

[B]

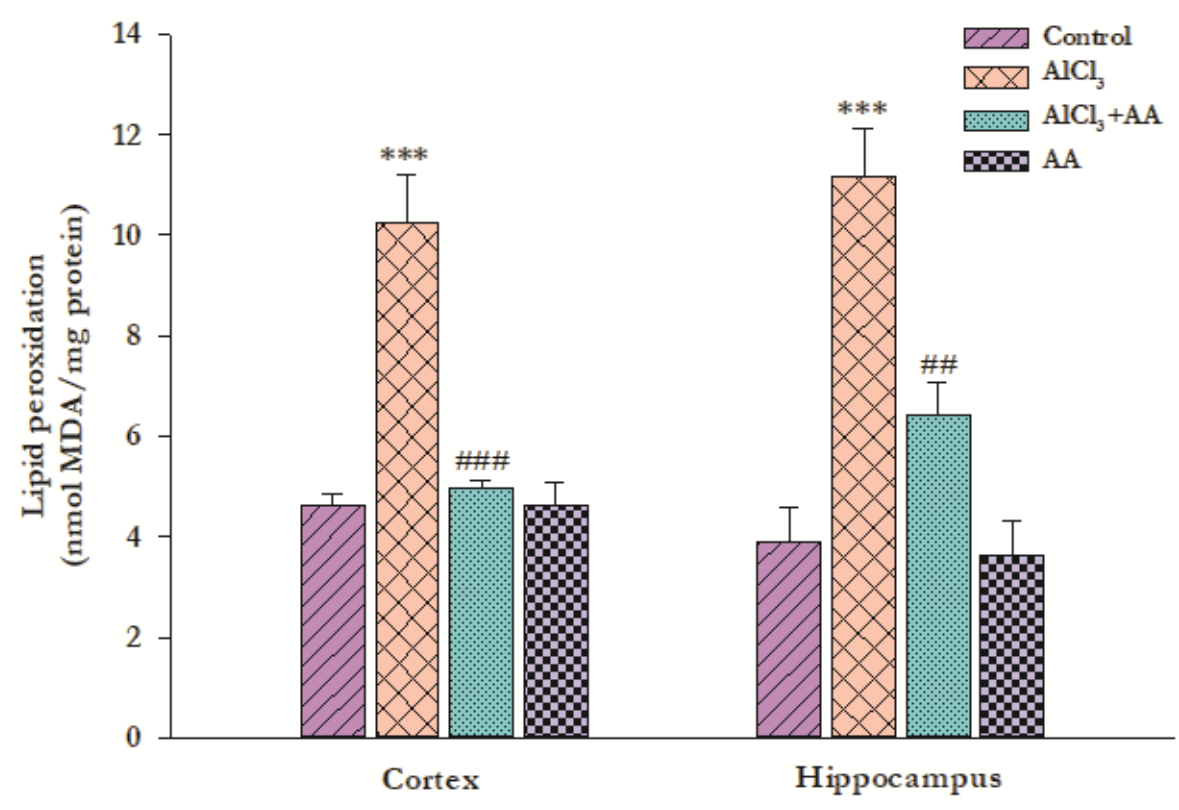

Fig 3

\section{Figure 3}

Effect of AA treatment on AChE activity and LPO in the cortex and hippocampus of rats. (a) AChE activity and (b) LPO. Data are mean \pm SEM of four rats. ${ }^{*} \leq \leq 0.05 ; * \star P \leq 0.01 ; * \star * P \leq 0.001$ significantly different from control group and \#P $\leq 0.05$; \#\# $\leq 0.01$; \#\# $\mathrm{A} \leq 0.001$ compared with AlCl3-intoxicated group. 
[A]
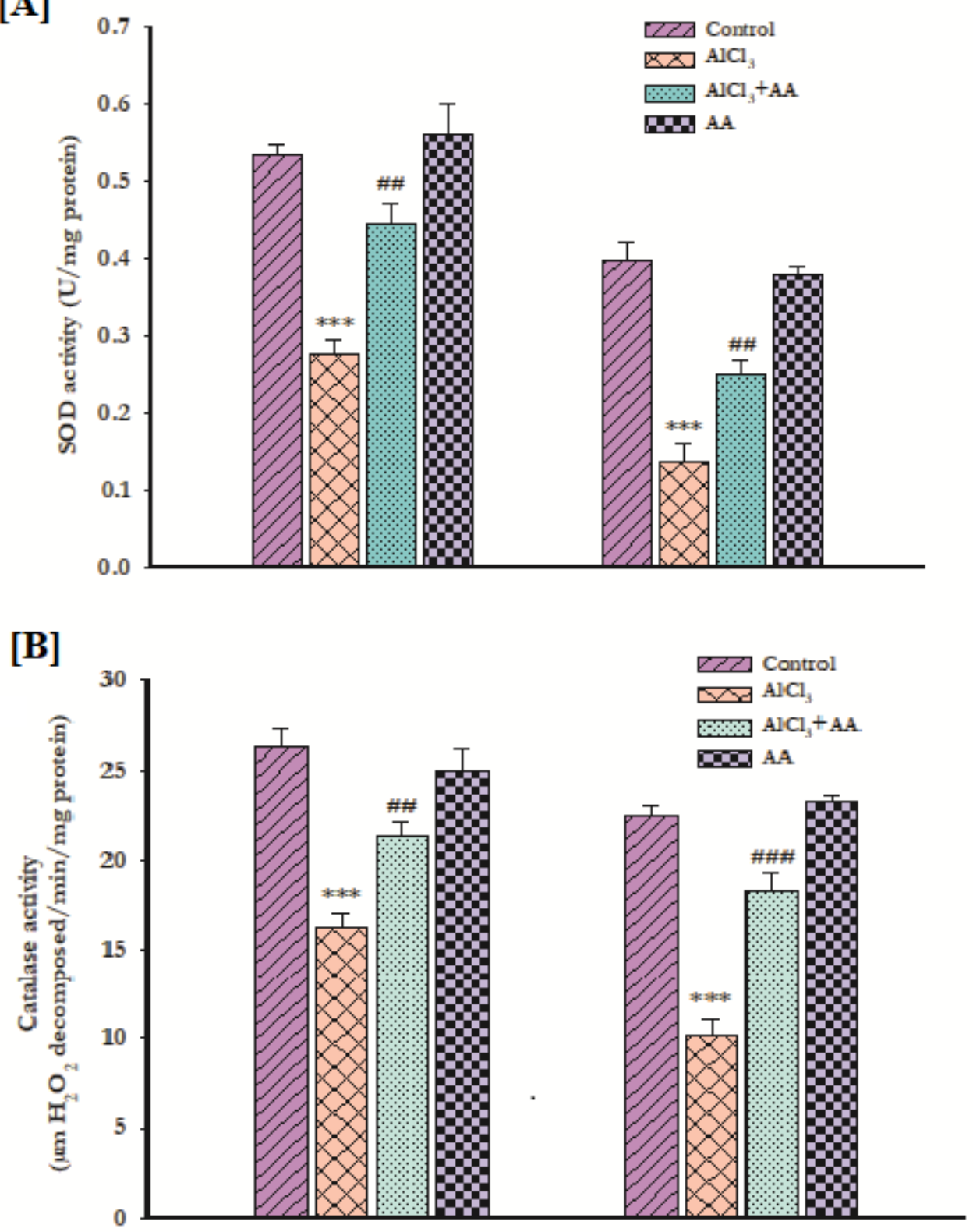

Fig. 4

Figure 4

Effect of AA treatment on antioxidant enzyme activities in the cortex and hippocampus of AlCl3intoxicated rats. (a) SOD and (b) CAT activity. Data are mean \pm SEM of four rats. ${ }^{*} \leq 0.05 ; * * P \leq 0.01$; $\star \star \star P \leq 0.001$ significantly different from control group and \#P $\leq 0.05 ; \# \# \mathrm{P} \leq 0.01 ; \# \# \# \mathrm{P} \leq 0.001$ compared with $\mathrm{AlCl} 3$-intoxicated group. 


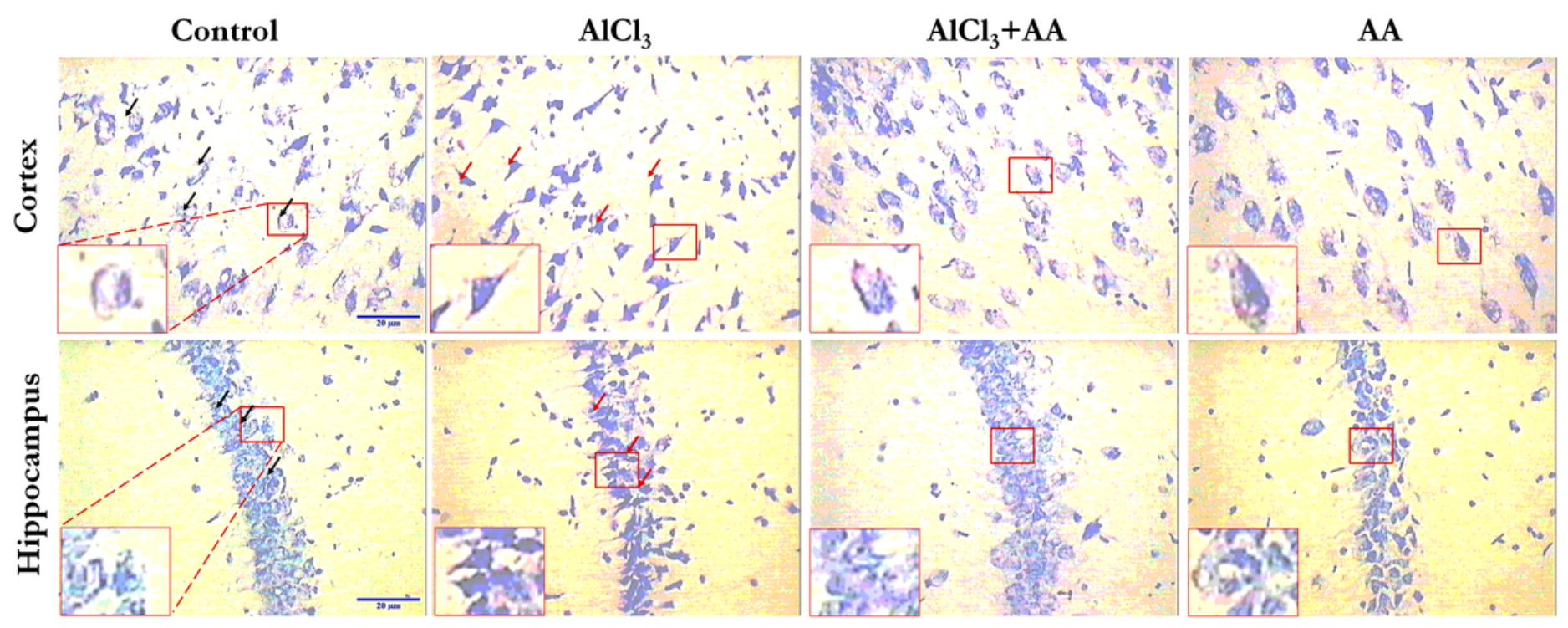

Fig. 5

Figure 5

Representative images of CV staining showing viable (black arrow) and pyknotic cells (red arrows) in the cortex and hippocampus of AlCl3-intoxicated and AA-treated rats. 


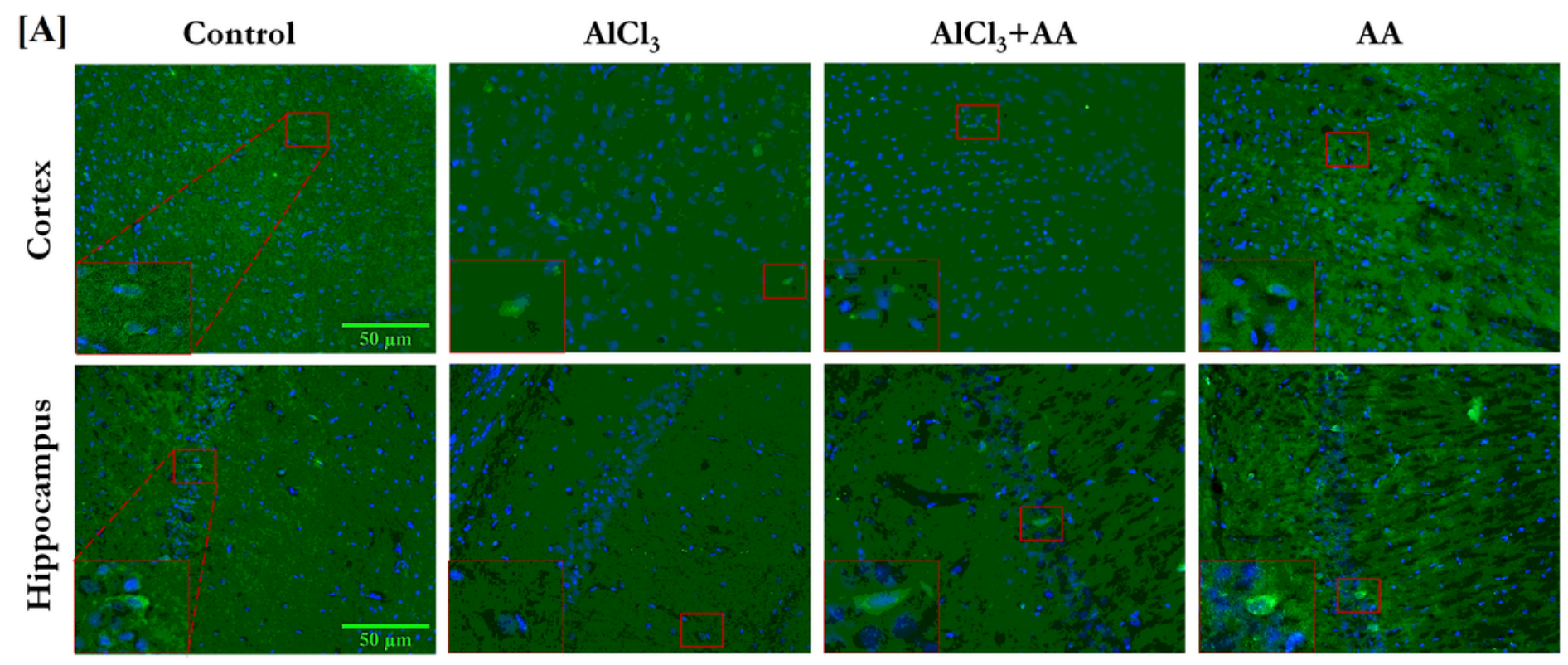

[B]
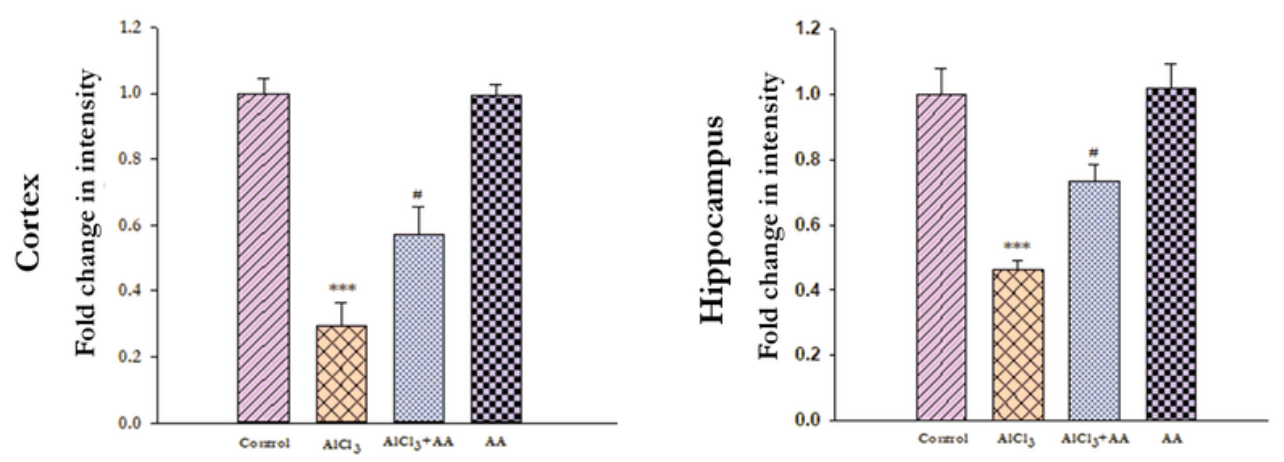

Fig. 6

\section{Figure 6}

Effect of AA treatment on neuronal density in the cortex and hippocampus of the AlCl3-intoxicated rats.

A) NeuN staining in cortex and hippocampus. B) Quantitative analysis of NeuN immuno-stained cells.

Data are mean \pm SEM of four rats. ${ }^{\star} P \leq 0.05 ; \star \star P \leq 0.01 ; * \star \star P \leq 0.001$ significantly different from control group and \#P $\leq 0.05 ; \# \# \mathrm{P}<0.01 ; \# \# \mathrm{P} \leq 0.001$ compared with AlCl3-intoxicated group. 

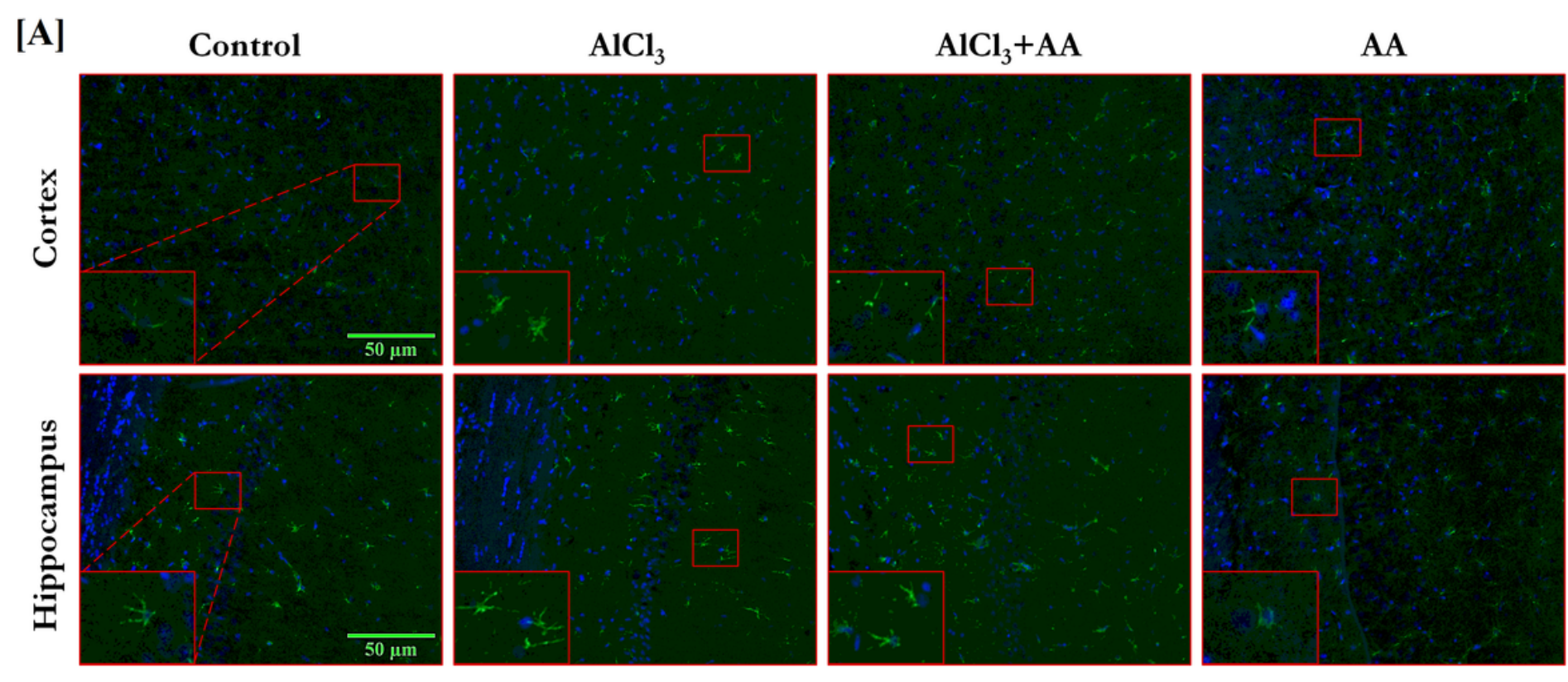

[B]
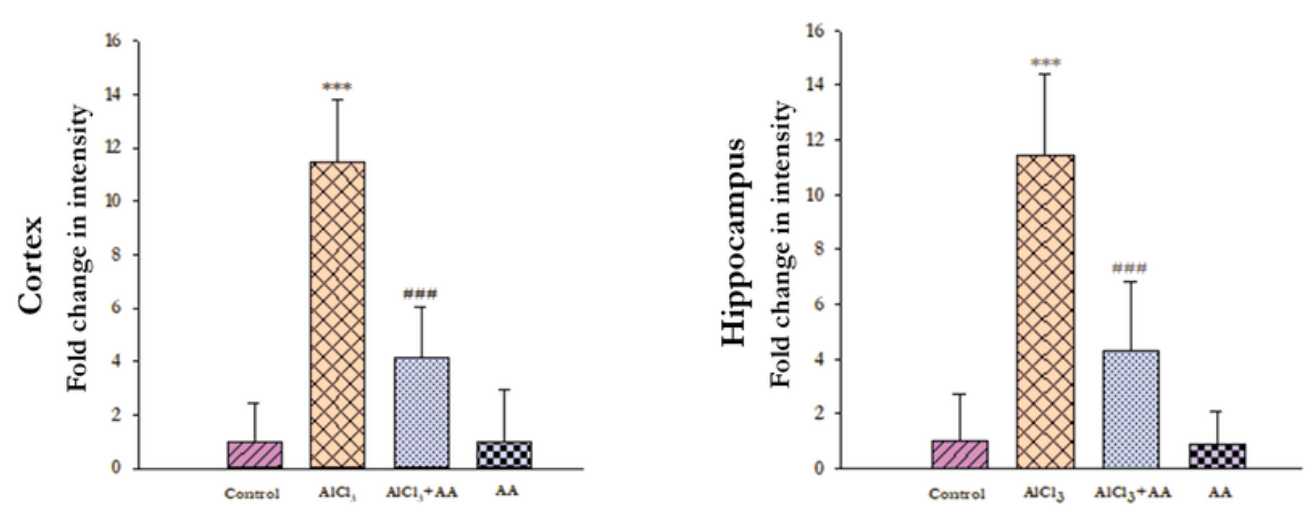

Fig. 7

\section{Figure 7}

Effect of AA treatment on astrocytes activation in the cortex and hippocampus of AlCl3-intoxicated rat brain. A) GFAP immunostaining in cortex and hippocampus. B) Quantitative analysis of GFAP immunostained cells. Data are mean \pm SEM of four rats. ${ }^{*} \mathrm{P} \leq 0.05 ; * \star \mathrm{P} \leq 0.01 ; * \star \star P \leq 0.001$ significantly different from control group and \#P $\leq 0.05 ; \# \# \mathrm{P} \leq 0.01$; \#\# $\mathrm{AP} 0.001$ compared with AlCl3-intoxicated group. 